\title{
Psychological burden among women with polycystic ovarian syndrome in Oman: a case-control study
}

This article was published in the following Dove Press journal: International Journal of Women's Health

\author{
Maha AH Sulaiman' \\ Yahya M Al-Farsi' \\ Maha M Al-Khaduri² \\ Mostafa I Waly \\ Jumana Saleh ${ }^{4}$ \\ Samir Al-Adawi ${ }^{5}$ \\ 'Department of Family Medicine \\ and Public Health, ${ }^{2}$ Department of \\ Obstetrics and Gynecology, College \\ of Medicine and Health Sciences, \\ ${ }^{3}$ Department of Nutrition and Food \\ Sciences, College of Agricultural \\ and Marine Sciences, ${ }^{4}$ Department \\ of Biochemistry, ${ }^{5}$ Department of \\ Behavioral Medicine, College of \\ Medicine and Health Sciences, Sultan \\ Qaboos University, Al-Khoudh, \\ Muscat, Sultanate of Oman
}

Purpose: Previous studies in Euro-American populations have shown that women with polycystic ovarian syndrome (PCOS) have increased levels of "psychological burden". While PCOS has been reported in Arab countries such as Oman, there is a dearth of studies of the occurrence of psychological burden among PCOS women in the Arab region. This study aimed to compare sociodemographic and clinical characteristics of PCOS women diagnosed with non-PCOS women and prevalence of severity of depression, anxiety and stress and to explore the association between PCOS and indices of psychological disturbances after adjusting for potential confounding factors.

Patients and methods: This hospital-based case-control study was conducted among women aged 16-49 years. The study included 52 women diagnosed with PCOS (as per Rotterdam 2003 criteria) and 60 control who were PCOS-free. The presence of psychological burden depression, anxiety and stress - was quantified using Depression, Anxiety and Stress Scale-21 (DASS-21).

Results: The crude odds ratios (ORs) generated by logistic regression models indicated an increased risk of depression, anxiety and stress among women with PCOS compared to controls. The adjusted OR also indicated an increased risk of depression (OR $=1.10 ; 95 \%$ confidence interval $[\mathrm{CI}] 0.50,2.43)$, anxiety $(\mathrm{OR}=1.09 ; 95 \% \mathrm{CI} 0.47,2.52)$ and stress $(\mathrm{OR}=1.45 ; 95 \% \mathrm{CI}$ $0.68,3.12)$, However, no statistical differences were observed along the three psychological distresses $(p>0.05)$ between the two study groups.

Conclusion: The study indicates that the presence of PCOS is associated with an increased risk of psychological burden. If this study will withstand further scrutiny, meeting psychological needs of such population would need to be contemplated.

Keywords: PCOS, depression, anxiety, stress, Oman, case-control

\section{Introduction}

Polycystic ovarian syndrome (PCOS) is a genetically complex endocrine disorder characterized with clinical features of menstrual disorders, infertility, high levels of masculinizing hormones and metabolic syndrome. ${ }^{1}$ Hyperandrogenism manifests as hirsutism, acne and alopecia. ${ }^{2}$ Lifestyle changes, medications and surgery are considered the mainstay of management of PCOS. ${ }^{3}$

PCOS had been shown to trigger psychological burden. ${ }^{4}$ Several recent systematic reviews and meta-analyses testified to this view. Barry et $\mathrm{al}^{5}$ reviewed a series of studies that examined differences in psychological burden of women with PCOS and those without PCOS. The authors suggested that women with PCOS tended to have elevated scores of anxiety and depression compared to non-PCOS women. In another
Correspondence: Yahya M Al-Farsi Department of Family Medicine and Public Health, College of Medicine and Health Sciences, Sultan Qaboos University, PO Box 35, 123 Al-Khoudh,

Muscat, Sultanate of Oman

$\mathrm{Tel}+96824143430$

Mob +96899383220

Fax +96824 4I 3300

Email ymfarsi@squ.edu.om 
meta-analysis, Veltman-Verhulst et $\mathrm{al}^{6}$ concluded that women with PCOS tended to exhibit significantly more emotional distress compared to women without PCOS. In their systematic review, Blay et $\mathrm{al}^{7}$ indicated that anxiety and depression symptoms were more common among patients with PCOS. More recently, Cooney et $\mathrm{al}^{8}$ have conducted a systematic review, and the surveyed studies unequivocally suggested that the presence of PCOS was an independent predictor of increased risk of psychological disorders such as depression and anxiety.

Despite that the World Health Organization estimated that there are 116 million women with PCOS worldwide, which would a mount to $3.4 \%$ of women population, ${ }^{9}$ there is dearth of studies of psychological sequel of PCOS from non-Western countries with few exceptions. ${ }^{10-14}$ One of the non-Western countries, Sultanate of Oman, a country located in the southern tip of Arabian Peninsula, had reported the magnitude of PCOS. Al Khaduri et $\mathrm{l}^{15}$ reported the hospital prevalence of PCOS among Omani women aged 25-34 years to be 7.1 cases/1,000 women. The authors projected the overall standardized prevalence estimate for the Omani population to be 2.8 cases $/ 1,000$ women $(95 \%$ confidence interval [CI] $0.7,9.6)$. Despite speculated magnitude, to our knowledge no study has been forthcoming on the presence of psychological disturbances among women with PCOS in Oman.

This study was conducted in Oman, an Arab Middle East country that stretches across $\sim 309,500 \mathrm{~km}^{2}$. Its population is estimated to be 4.49 million, and the country is classified by the World Bank as a "high-income economy" among the emerging economies. ${ }^{16}$ In the year 2016, women in Oman constituted $34.6 \%$ of the total population. ${ }^{17}$

In Oman, preliminary studies reported that female population seen at primary health care facilities experienced psychological distresses. ${ }^{18}$ A cross-sectional study conducted among Omani students reported that $28 \%$ of female students had depression. ${ }^{19}$ A similar study conducted on medical trainees in Oman showed that the prevalence of depression among females was $12.2 \%{ }^{20}$ Al-Salmani et $\mathrm{al}^{21}$ showed in a cross-sectional study conducted on 2005 participants attending different primary health care centers in Oman that the prevalence of depression among females was $8.8 \%$.

The overall aim of this study was to examine whether there was a variation in the performance of indices of depression, anxiety and stress among PCOS women compared to non-PCOS women.

The specific objectives were 1) to compare selected sociodemographic characteristics among PCOS women and controls; 2) to estimate the prevalence and severity of depression, anxiety and stress among cases and non-cases and 3 ) to explore the association between PCOS and indices of psychological disturbances after adjusting for potential confounding factors.

\section{Patients and methods}

This case-control study was conducted over the period from June 2016 to March 2017 among women attending Sultan Qaboos University Hospital (SQUH), a tertiary teaching hospital in Oman. The study was approved by the medical research ethics committee of College of Medicine and Health Sciences, SQUH (MREC 826).

Allowing an error rate of $2.5 \%$, the level of significance (type 1 error) of $5 \%$ and $95 \% \mathrm{CI}$ and with a priori estimate that $12 \%$ of participants would have the psychological distress, the computer program indicated that a sample size of 112 participants was required to achieve a power of $85 \%$ of the study.

\section{Participants}

The study participants included 112 Omani women within the reproductive age: 52 PCOS cases and 60 controls of overall similar ethnicity, culture and quality of care. The cases were selected by convenience sampling, while controls were selected by simple random sampling.

\section{Ascertainment and selection of cases}

PCOS diagnosis was ascertained according to the gold standard Rotterdam criteria, which state that PCOS syndrome is characterized by the presence of two of the following three classical features of PCOS: oligo- and/or anovulation, clinical and/or biochemical signs of hyperandrogenism and polycystic ovaries on ultrasonography with the exclusion of the related disorders. ${ }^{22}$ This study excluded women who were pregnant or postmenopausal or with specific neoplasms or underlying disease of the pituitary or adrenal glands.

A total of 58 PCOS cases from the Obstetrics and Gynecology (OBGYN) Outpatient Clinic at SQUH were identified as eligible participants for the study. They were approached, and 52 PCOS women agreed to participate, yielding a response rate of $90 \%$. All PCOS cases were examined by two senior obstetricians specialized in fertility, both of whom were experienced in clinical management of PCOS. Agreement between the two obstetricians about PCOS ascertainment was found to be $96 \%$. The percentage agreement was improved to $100 \%$ upon independent review and discussion of patients' profiles by the research team. 


\section{Selection of controls}

Controls were randomly selected from eligible outpatients at the OBGYN Outpatient Clinic. Eligible controls were defined as non-menopausal, nonpregnant women within the reproductive age who were not known to have PCOS or any other endocrine or metabolic disturbances that might be related to or confused with PCOS.

The enrolled controls were drawn from a random sample of 238 eligible participants who had visited SQUH during the study period. The eligible controls who fulfilled inclusion and exclusion criteria were 73 . Of this group, only 62 were recruited due to either refusal of the participant or incomplete information, resulting in a response rate of $85 \%$. Each control participant was clinically examined by two senior obstetricians to exclude the possibility that they may have had subclinical PCOS features. Percentage agreement between the assessments of both physicians was found to be $96 \%$. Two women were excluded from the control group because they were pregnant.

\section{Study tools}

\section{Study questionnaire}

A questionnaire was designed to meet the objectives of this study. The questionnaire included several sections: 1) sociodemographic information; 2) relevant comorbidities; 3) clinical and dietary characteristics and 4) anthropometric measurements. The questionnaire was standardized and validated, as described elsewhere (unpublished data). ${ }^{23}$ It was reported that the global psychometric assessment of the questionnaire indicated that the overall validity and reliability were both high (Spearman's correlation of $r=0.80$ and Cohen's kappa of 0.83 , respectively).

\section{Depression, Anxiety and Stress Scale (DASS-2I)}

DASS-21 is a self-reported screening form designed to measure the negative emotional state of depression, anxiety and stress. ${ }^{24}$ The depression subscale measures hopelessness, low self-esteem and low positive affect; the anxiety subscale evaluates autonomic arousal, skeletal muscle effects, situational anxiety and subjective experience of anxious effect and the stress subscale assesses tension, agitation, over reactivity and impatience. There are 21 questions in DASS-21; seven questions for each of depression, anxiety and stress.

Participants are asked to use 4-point frequency scales to rate the severity to which they have experienced each state over the past 1 week. Scores for depression, anxiety and stress are calculated by summing the scores for the relevant items. The final score of each item group (depression, anxiety and stress) is multiplied by 2 . For theoretical reason, the scale was categorized into "mild", "moderate" and "severe" as detailed elsewhere. ${ }^{25}$ For depression, the cutoff values for mild, moderate and severe were 10, 14 and 21, respectively. For anxiety, the cutoff values were 8,10 and 15 , respectively, and for stress, the cutoff values were 15, 19 and 26, respectively. ${ }^{24,25}$

Both English and non-English versions were reported to have high internal consistency (Cronbach's alpha scores of >0.7). DASS-21 had been validated in different Englishspeaking and non-English-speaking populations, including Arab populations, and it was found to be adequate compared to the gold standard measures, semi-structured interviews such as Composite International Diagnostic Interview (CIDI) based on the Diagnostic and Statistical Manual of Mental Disorders (DSM) ${ }^{26-31}$ DASS-21 has been previously used for Omani population, and its psychometric properties were found adequate - the Cronbach's $\alpha$ for the three subscales was high. ${ }^{32}$

\section{Data collection}

Data were collected based on standardized interviews performed by the research team which was supported by qualified nurses. A written informed consent was obtained, and the participants were informed that they were free to refuse, participate or withdraw at any time without any disadvantage or prejudice. Parents or legal guardians of the participants younger than 18 years provided written informed consent on behalf of the participants.

\section{Data analysis}

The case and control groups were compared with respect to sociodemographics and selected clinical characteristics. Chi-square analyses were used to evaluate the statistical significance of differences among proportions of categorical data. The nonparametric Fisher's exact test (two tailed) replaced the chi-square test in case of small sample size where the expected frequency was $<5$ in any of the cells in $2 \times 2$ tables. The odds ratios (ORs) and 95\% CIs obtained from logistic regression modeling were taken as the measures of association between PCOS and selected risk factors. Potential confounders were adjusted for using multivariate logistic regression modeling.

\section{Results}

Overall, a total of 112 women were included, of whom there were 52 (46.4\%) PCOS cases and 60 (53.6\%) controls. Table 1 lists the sociodemographic characteristics of 
Table I Sociodemographic and clinical characteristics among participants by study groups, Oman, 2017

\begin{tabular}{|c|c|c|c|c|}
\hline Characteristics & $\begin{array}{l}\text { Total } \\
(\mathbf{N}=|| 2), \\
\text { n (\%) }\end{array}$ & $\begin{array}{l}\text { Cases } \\
(n=52) \\
n(\%)\end{array}$ & $\begin{array}{l}\text { Controls } \\
(n=60), \\
n(\%)\end{array}$ & $p$-value \\
\hline Age (years) & & & & 0.33 \\
\hline$\leq 25$ & $17(15.2)$ & $10(19.2)$ & $7(11.6)$ & \\
\hline $26-34$ & $65(58.0)$ & $31(59.6)$ & $34(56.7)$ & \\
\hline$\geq 35$ & $30(26.8)$ & II (2I.2) & $19(31.7)$ & \\
\hline Marital status & & & & 1.00 \\
\hline Single & $6(5.4)$ & $3(5.8)$ & $3(5.0)$ & \\
\hline Married & $106(94.6)$ & 49 (94.2) & $57(95.0)$ & \\
\hline Education & & & & 0.21 \\
\hline School educated & $51(45.5)$ & $27(51.9)$ & $24(40.0)$ & \\
\hline University educated & $61(54.5)$ & $25(48.1)$ & $36(60.0)$ & \\
\hline Employment status & & & & 0.73 \\
\hline Employed & $58(5 \mathrm{I} .8)$ & $26(50.0)$ & $32(53.3)$ & \\
\hline Unemployed & $54(48.2)$ & $26(50.0)$ & $28(46.7)$ & \\
\hline \multicolumn{2}{|l|}{ Monthly income (OMR) } & & & 0.31 \\
\hline$<400$ & $18(16.1)$ & $9(17.3)$ & $9(15.0)$ & \\
\hline $400-799$ & $27(24.1)$ & $15(28.8)$ & $12(20.0)$ & \\
\hline $800-1,199$ & $20(17.8)$ & II (2I.2) & $9(15.0)$ & \\
\hline$\geq 1,200$ & $47(42.0)$ & $17(32.7)$ & $30(50.0)$ & \\
\hline Irregular menses & $46(4 I .1)$ & 37 (7I.2) & $9(15.0)$ & 0.001 \\
\hline Presence of hirsutism & $49(43.8)$ & $40(76.9)$ & $9(15.0)$ & 0.001 \\
\hline Presence of acne & $31(27.7)$ & $21(40.4)$ & $10(16.7)$ & 0.01 \\
\hline \multicolumn{2}{|l|}{ Number of pregnancies } & & & 0.003 \\
\hline 0 & $28(25.0)$ & $20(38.4)$ & $8(13.3)$ & \\
\hline $1-4$ & $69(61.6)$ & $29(55.8)$ & $40(66.7)$ & \\
\hline$\geq 5$ & $15(13.4)$ & $3(5.8)$ & $12(20.0)$ & \\
\hline
\end{tabular}

Abbreviation: OMR, Omani Rials.

PCOS cases and controls. The majority (58\%) of participants were in the age category of 26-34 years. The mean ages in the case and control groups were $29.3 \pm 5.0$ years and $32.0 \pm 6.2$ years, respectively, with a significant difference between the two groups $(p=0.01)$. In addition, almost half of the study participants had acquired university education (54.5\%) and were employed (51.8\%). There was no significant difference between PCOS cases and controls in terms of education, employment and income. Table 1 also lists selected clinical characteristics of participants. Overall, the proportions of PCOS women with irregular menses (71.2\%), hirsutism (76.9\%) and acne (40.4\%) were significantly higher than that among non-PCOS women $(p \leq 0.05)$. The proportion of PCOS women who never got pregnant (38.4\%) was significantly higher compared to non-PCOS women (13.3\%).

Table 2 lists the prevalence of depression, anxiety and stress among all participants and the study groups. In general, around half of the overall participants had depression and stress and $63.4 \%$ participants exhibited anxiety. Although, the data did not show any significant statistical difference for the psychological distress between the two groups $(p>0.05)$, the prevalence of PCOS women having depression, anxiety and stress was higher compared to non-PCOS women. Generally, anxiety was the most prevalent psychological stress reported among overall participants and in each study group.

Table 3 demonstrates the levels of severity of stress, anxiety and depression among cases and controls. Mild depression and severe depression were higher among PCOS women compared to non-PCOS women. In addition, the proportion of PCOS women who suffered from moderate anxiety and stress was higher than that of non-PCOS women. Nonetheless, all three parameters did not exhibit any significant difference between cases and controls $(p>0.05)$.

Table 4 depicts both crude and adjusted analyses of depression, anxiety and stress among case and control groups. The crude ORs indicated that increased risks of depression, anxiety and stress were associated with PCOS. After adjustment for possible confounders (age and education), the adjusted ORs also indicated an increased risk for depression $(\mathrm{OR}=1.10 ; 95 \%$ CI $0.50,2.43)$, anxiety $(\mathrm{OR}=1.09$; $95 \%$ CI $0.47,2.52)$ and stress $(\mathrm{OR}=1.45 ; 95 \%$ CI 0.68 , 3.12). Nonetheless, the associations were not statistically significant $(p>0.05)$.

\section{Discussion}

Several studies had shown that women with PCOS tend to exhibit increased levels of emotional distress. ${ }^{4-8}$ Most of the studies have generally emanated from Euro-American

Table 2 Prevalence of depression, anxiety and stress among participants by study groups, Oman, 2017

\begin{tabular}{lllll}
\hline Categories & Total $(\mathbf{N}=\mathbf{I} \mathbf{I})$ & Cases $(\mathbf{n}=\mathbf{5 2})$ & Controls $(\mathbf{n}=\mathbf{6 0})$ & $\mathbf{p}$-value \\
\hline Depression $(\mathbf{n})$ & 57 & 27 & 30 & 0.84 \\
Prevalence $^{\mathrm{a}}(95 \% \mathrm{Cl})$ & $50.9(41.8,60.0)$ & $51.9(38.7,64.9)$ & $30.0(37.7,62.3)$ & \\
Anxiety $(\mathbf{n})$ & 71 & 35 & $60.0(47.4,71.4)$ & 0.42 \\
Prevalence $(95 \% \mathrm{Cl})$ & $63.4(54.2,71.7)$ & $67.3(53.7,78.5)$ & 27 & 0.26 \\
Stress $(\mathbf{n})$ & 56 & 29 & $45.0(33.1,57.5)$ & \\
Prevalence $(95 \% \mathrm{Cl})$ & $50.0(40.9,59.1)$ & $55.8(42.3,68.4)$ & & \\
\hline
\end{tabular}

Note: aPrevalence per 100 persons.

Abbreviation: $\mathrm{Cl}$, confidence interval. 
Table 3 Levels of severity of depression, anxiety and stress among participants by study groups, Oman, 2017

\begin{tabular}{lllll}
\hline Characteristics & $\begin{array}{l}\text { Total, } \\
\mathbf{n}(\%)\end{array}$ & $\begin{array}{l}\text { Cases, } \\
\mathbf{n}(\%)\end{array}$ & $\begin{array}{l}\text { Controls, } \\
\mathbf{n}(\%)\end{array}$ & p-value \\
\hline Depression (n) & 57 & 27 & 30 & 0.53 \\
Mild & $16(28.1)$ & $9(33.3)$ & $7(23.3)$ & \\
Moderate & $21(36.8)$ & $8(29.6)$ & $13(43.3)$ & \\
Severe & $20(35.1)$ & $10(37.1)$ & $10(33.4)$ & \\
Anxiety (n) & 71 & 35 & 36 & 0.24 \\
Mild & $10(14.1)$ & $5(14.3)$ & $5(13.9)$ & \\
Moderate & $22(31.0)$ & $14(40.0)$ & $8(22.2)$ & \\
Severe & $39(54.9)$ & $16(45.7)$ & $23(63.9)$ & \\
Stress (n) & 56 & 29 & 27 & 0.75 \\
Mild & $18(32.1)$ & $9(31.0)$ & $9(33.3)$ & \\
Moderate & $15(26.8)$ & $9(31.0)$ & $6(22.2)$ & \\
Severe & $23(41.1)$ & $11(38.0)$ & $12(44.5)$ & \\
\hline
\end{tabular}

populations. To our knowledge, there are few studies from the Arabic-speaking populations. To fill the gap in literature, this study has embarked to compare sociodemographic and clinical characteristics of those diagnosed with PCOS with those without to report the prevalence of severity of depression, anxiety and stress as defined by DASS- 21 and to tease out the association after adjusting for potential confounding factors.

Our study showed that most participants were middle aged with a significant difference in age between the two study groups. This finding had signaled that age might have a confounding effect, so it was adjusted for in the study.

Overall, our data showed that PCOS women manifested clinical symptoms of irregular menses $(71.2 \%)$, hirsutism (76.9\%), acne (40.4\%) and infertility (38.4\%) compared to the non-PCOS women. This clinical profile suggests that Omani women with PCOS might have similar phenotype to those reported among South Asian women with PCOS. Wijeyaratne et $\mathrm{al}^{33}$ have compared ethnic differences in

Table 4 Logistic regression analysis of depression, anxiety and stress for the study groups, Oman, 2017

\begin{tabular}{|c|c|c|c|c|}
\hline \multirow[t]{2}{*}{ Outcome } & \multirow{2}{*}{$\begin{array}{l}\text { Crude } \\
\text { OR }(95 \% \mathrm{Cl})\end{array}$} & \multirow[t]{2}{*}{$p$-value } & \multirow{2}{*}{$\begin{array}{l}\text { Adjusted }^{\mathrm{a}} \\
\text { OR }(95 \% \mathrm{CI})\end{array}$} & \multirow[t]{2}{*}{$p$-value } \\
\hline & & & & \\
\hline Depression & & 0.84 & & 0.81 \\
\hline Controls & 1.0 & & 1.0 & \\
\hline Cases & I.08 (0.5।, 2.27) & & $1.10(0.50,2.43)$ & \\
\hline Anxiety & & 0.42 & & 0.84 \\
\hline Controls & 1.0 & & 1.0 & \\
\hline Cases & $1.37(0.63,2.98)$ & & $1.09(0.47,2.52)$ & \\
\hline Stress & & 0.26 & & 0.34 \\
\hline Controls & 1.0 & & 1.0 & \\
\hline Cases & $1.54(0.73,3.25)$ & & $1.45(0.68,3.12)$ & \\
\hline
\end{tabular}

Note: ${ }^{A}$ Adjusted for age and education.

Abbreviations: $\mathrm{OR}$, odds ratio; $\mathrm{Cl}$, confidence interval. the clinical and biochemical characteristics of South Asian versus Caucasian women with PCOS residing in the UK. The data showed that acne was more prevalent in South Asian women (66\% vs 30\%). Indices of hirsutism and secondary infertility were significantly higher in South Asians compared to Caucasians. Mani et $\mathrm{al}^{34}$ have investigated the clinical differences between White and South Asian women with PCOS, and the results suggested a higher prevalence of hirsutism ( $89 \%$ vs $77 \%$ ) as well as oligomenorrhea $(81 \%$ vs $72 \%$ ) in South Asian PCOS women compared to the Whites. Oman is located at the cross-road between Asia and Middle East. It is therefore possible that there are shared genetic, geographical and sociocultural factors that rendered Oman population to have phenotypic similarity with their South Asian counterpart.

To our knowledge, this is the first study in Oman and the Arab region to examine the magnitude of psychological disturbances and their correlates among PCOS women using DASS-21. Unlike other symptom checklists, DASS-21 is equipped to explore the presence and magnitude of depression, anxiety and stress. This study showed that more than half of the participants had at least one indicator of psychological burden, and PCOS women had higher prevalence estimates compared to non-PCOS women. Similar studies showed that the prevalence of depression and anxiety were higher among PCOS cases than controls. ${ }^{14,35}$ The most prevalent psychological burden reported in literature was anxiety. In the systematic review reported by Dokras et al, ${ }^{36}$ the rate of generalized anxiety symptoms was noted to be higher in PCOS women than controls. The preponderance of anxiety in people with PCOS has been also reported by others. ${ }^{37,38}$ The trend in the present study is congruent with the existing literature that supports a view that the prevalence of psychological burden in women with PCOS is greater than in the general population. ${ }^{39,40}$ Overall, this study suggests that psychological burden is higher among people with PCOS compared to those with non-PCOS in Oman. The difference was still persistent after adjusting for potential confounding factors.

The pathophysiology of PCOS can provide a possible explanation for the observed increased risk of psychological disturbances. Although the exact pathophysiological mechanism of PCOS is not fully understood, ${ }^{41}$ there are many theories that have been proposed to explain the pathogenesis of PCOS. One theory states that there is an alteration in gonadotropin-releasing hormone secretion, which results in increased luteinizing hormone (LH) secretion, leading to the production of more androgens. ${ }^{2}$ Another theory states 
that a high insulin level also suppresses hepatic production of sex hormone binding globulin, leading to an increase in the unbound level of testosterone that subsequently results in hirsutism and acne. ${ }^{41}$ Empirically, evidence had suggested that both high insulin and androgen change monoamine balance, which is known to result in mood disturbances in PCOS patients. ${ }^{42}$

It is possible that psychological burden could arise due to social impact of the PCOS. Decreased sexual satisfaction, obesity and problems with body image and feminine identity are common among the "victims of PCOS," would trigger psychological burden. ${ }^{44-46}$ It has also been reported that the disturbed body image in adolescents with PCOS may arise from the presence of acne and hirsutism which, in turn, trigger psychological burden. ${ }^{42}$ One sequel of PCOS is infertility, which can cause social pressure in a society like Oman where women's identity is defined in terms of procreation. ${ }^{47}$

Our study showed that mild depression and severe depression were higher among PCOS women compared to non-PCOS women. In addition, the proportion of PCOS women who suffered from moderate anxiety and stress was higher than that of non-PCOS women. Similar patterns were reported by other studies. In a cross-sectional study of women with PCOS, results showed that a larger percentage of women experienced more severe levels of anxiety than depression, and $36 \%$ of women were classified as moderately or severely anxious. Comparatively, the majority of PCOS women with depression reported to be mildly depressed, followed by those with moderate and severe depression. ${ }^{37}$

\section{Limitations}

These types of psychosocial studies are likely to be hampered by some limitations. First, the data were collected in a hospital setting, and therefore, the study lacks the vigor of community studies where there are likely to be people with PCOS who have not been referred to the hospital. Second, self-reporting of the questionnaire could be affected by recall bias. Thus, misclassification error could be rampant. To circumvent such a limitation, concerted effort was made to maintain the uniformity of data collection procedures across the study groups, which ensured that any misclassification error that occurred would most likely have been non-differential across the study groups. Moreover, data showed less significant differences for the psychological indices since the control group included women who suffered from infertility and other gynecological disorders, which may have led to the development of psychological disturbances.
Therefore, it would have been useful to compare PCOS women to "healthy" women attending a health facility for routine health screening in order to get more significant differences for the psychological indices.

\section{Conclusion}

This study explored psychological burden among Omani women with PCOS. The data suggested that women with PCOS have similar sociodemographic and risk factor profile as those reported from South Asia women population. After adjusting for potential confounding factors, women with PCOS outperformed non-PCOS women. Among three types of psychological burden, anxiety disorder was the most highly endorsed. These findings could prove useful for care providers targeting women at risk of having PCOS. More rigorous population-based studies with larger sample sizes and integrating additional variables are needed to further explore the link between PCOS and psychological disturbances. In addition to the effective medical treatments that aim at improving PCOS-related and subsequently reducing psychological distress, it is worth considering the integration of psychological counseling in primary health centers and OBGYN clinics in Oman to further improve quality of life of women with PCOS.

\section{Acknowledgment}

The authors would like to acknowledge physicians and nursing staff of OBGYN Clinic at SQUH for their valuable support in conduct of this study.

\section{Disclosure}

The authors report no conflicts of interest in this work.

\section{References}

1. Azziz R, Woods KS, Reyna R, Key TJ, Knochenhauer ES, Yildiz BO. The prevalence and features of the polycystic ovary syndrome in an unselected population. J Clin Endocrinol Metab. 2004;89(6):2745-2749.

2. Ehrmann DA. Polycystic ovary syndrome. NEngl J Med. 2005;352(12): $1223-1236$.

3. Harwood K, Vuguin P, DiMartino-Nardi J. Current approaches to the diagnosis and treatment of polycystic ovarian syndrome in youth. Horm Res Paediatr. 2007;68(5):209-217.

4. Teede H, Deeks A, Moran L. Polycystic ovary syndrome: a complex condition with psychological, reproductive and metabolic manifestations that impacts on health across the lifespan. BMC Med. 2010;8(1):41.

5. Barry JA, Kuczmierczyk AR, Hardiman PJ. Anxiety and depression in polycystic ovary syndrome: a systematic review and meta-analysis. Hum Reprod. 2011;26(9):2442-2451.

6. Veltman-Verhulst SM, Boivin J, Eijkemans MJ, Fauser BJ. Emotional distress is a common risk in women with polycystic ovary syndrome: a systematic review and meta-analysis of 28 studies. Hum Reprod Update. 2012;18(6):638-651.

7. Blay SL, Aguiar JVA, Passos IC. Polycystic ovary syndrome and mental disorders: a systematic review and exploratory meta-analysis. Neuropsychiatr Dis Treat. 2016;12:2895. 
8. Cooney LG, Lee I, Sammel MD, Dokras A. High prevalence of moderate and severe depressive and anxiety symptoms in polycystic ovary syndrome: a systematic review and meta-analysis. Hum Reprod. 2017;32(5):1075-1091.

9. Vos T, Flaxman AD, Naghavi M, et al. Years lived with disability (YLDs) for 1160 sequelae of 289 diseases and injuries 1990-2010: a systematic analysis for the Global Burden of Disease Study 2010. Lancet. 2013;380(9859):2163-2196.

10. Annagür BB, Kerimoglu ÖS, Tazegül A, Gündüz Ş, Gençoglu BB. Psychiatric comorbidity in women with polycystic ovary syndrome. J Obstet Gynaecol Res. 2015;41(8):1229-1233.

11. Hung J-H, Hu L-Y, Tsai S-J, et al. Risk of psychiatric disorders following polycystic ovary syndrome: a nationwide population-based cohort study. PLoS One. 2014;9(5):e97041.

12. Ghazeeri G, Fakih A, Abbas HA, Harajly S, Awwad J. Anxiety, cognitive, and depressive assessment in adolescents with polycystic ovarian syndrome: a pilot study. J Pediatr Adolesc Gynecol. 2013; 26(5):269-273.

13. Rassi A, Veras AB, dos Reis M, et al. Prevalence of psychiatric disorders in patients with polycystic ovary syndrome. Compr Psychiatry. 2010;51(6):599-602.

14. Hussain A, Chandel RK, Ganie MA, et al. Prevalence of psychiatric disorders in patients with a diagnosis of polycystic ovary syndrome in Kashmir. Indian J Psychol Med. 2015;37(1):66.

15. Al Khaduri M, Al Farsi Y, Al Najjar TAA, Gowri V. Hospital-based prevalence of polycystic ovarian syndrome among Omani women. Middle East Fertil Soc J. 2014;19(2):135-138.

16. World Bank.org [homepage on the Internet]. Available from: http:// data.worldbank.org/country/oman. Accessed May 28, 2017.

17. Trading Economics.com. [webpage on the Internet]. Available from: https://tradingeconomics.com/oman/population-female-percent-oftotal-wb-data.html. Accessed 4 November, 2017.

18. Al Lawati J, Al Lawati N, Al Siddiqui M, et al. Psychological morbidity in primary healthcare in Oman: a preliminary study. J Sci Res Med Sci. 2000;2:105-110.

19. Al-Busaidi Z, Bhargava K, Al-Ismaily A, et al. Prevalence of depressive symptoms among university students in Oman. Oman Med J. 2011; 26(4):235-239.

20. Al-Ghafri G, Al-Sinawi H, Al-Muniri A, et al. Prevalence of depressive symptoms as elicited by Patient Health Questionnaire (PHQ-9) among medical trainees in Oman. Asian J Psychiatr. 2014;8:59-62.

21. Al-Salmani A, Juma T, Al-Noobi A, et al. Characterization of depression among patients at urban primary healthcare centers in Oman. Int J Psychiatry Med. 2015;49(1):1-18.

22. The Rotterdam EA-SPCWG. Revised 2003 consensus on diagnostic criteria and long-term health risks related to polycystic ovary syndrome. Fertil Steril. 2004;81(1):19-25.

23. Al-Fazari M. Assessment of Risk Factors Related to Nutrition and Dietary Intake Among Omani Women with Polycystic Ovarian Syndrome [dissertation]. Muscat: Sultan Qaboos University; 2014.

24. Lovibond SH, Lovibond PF. Manual for the Depression Anxiety Stress Scales. 2nd ed. Sydney: Psychological Foundation; 1995.

25. Henry JD, Crawford JR. The short-form version of the Depression Anxiety Stress Scales (DASS-21): construct validity and normative data in a large non-clinical sample. Br J Clin Psychol. 2005;44(2):227-239.

26. Al-Gelban KS, Al-Amri HS, Mostafa OA. Prevalence of depression, anxiety and stress as measured by the Depression, Anxiety, and Stress Scale (DASS-42) among Secondary School Girls in Abha, Saudi Arabia. Sultan Qaboos Univ Med J. 2009;9(2):140-147.

27. Al-Gelban KS. Depression, anxiety and stress among Saudi adolescent school boys. J R Soc Promot Health. 2007;127(1):33-37.

28. Vignola RCB, Tucci AM. Adaptation and validation of the depression, anxiety and stress scale (DASS) to Brazilian Portuguese. J Affect Disord. 2014;155:104-109.
29. Tonsing KN. Psychometric properties and validation of Nepali version of the Depression Anxiety Stress Scales (DASS-21). Asian J Psychiatr. 2014;8:63-66.

30. Moussa MT, Lovibond P, Laube R, Megahead HA. Psychometric properties of an Arabic version of the Depression Anxiety Stress Scales (DASS). Res Soc Work Pract. 2017;27(3):375.

31. Al-Adawi S, Dorvlo A, Burke D, Moosa S, Al-Bahlani S. A survey of anorexia nervosa using the Arabic version of the EAT-26 and "gold standard" interviews among Omani adolescents. Eating Weight Disord. 2002;7(4):304-311.

32. Al-Farsi OA, Al-Farsi YM, Al-Sharbati MM, Al-Adawi S. Stress, anxiety, and depression among parents of children with autism spectrum disorder in Oman: a case-control study. Neuropsychiatr Dis Treat. 2016;12: 1943-1951.

33. Wijeyaratne $\mathrm{CN}$, Balen AH, Barth JH, Belchetz PE. Clinical manifestations and insulin resistance (IR) in polycystic ovary syndrome (PCOS) among South Asians and Caucasians: is there a difference? Clin Endocrinol (Oxf). 2002;57(3):343-350.

34. Mani H, Davies MJ, Bodicoat DH, et al. Clinical characteristics of polycystic ovary syndrome: investigating differences in White and South Asian women. Clin Endocrinol (Oxf). 2015;83(4):542-549.

35. Tan J, Wang QY, Feng GM, Li XY, Huang W. Increased risk of psychiatric disorders in women with polycystic ovary syndrome in Southwest China. Chin Med J (Engl). 2017;130(3):262-266.

36. Dokras A, Clifton S, Futterweit W, Wild R. Increased prevalence of anxiety symptoms in women with polycystic ovary syndrome: systematic review and meta-analysis. Fertil Steril. 2012;97(1):225.e-230.e.

37. Deeks AA, Gibson-Helm ME, Teede HJ. Anxiety and depression in polycystic ovary syndrome: a comprehensive investigation. Fertil Steril. 2010;93(7):2421-2423.

38. Benson S, Hahn S, Tan S, et al. Prevalence and implications of anxiety in polycystic ovary syndrome: results of an internet-based survey in Germany. Hum Reprod. 2009;24(6):1446-1451.

39. Bhattacharya SM, Jha A. Prevalence and risk of depressive disorders in women with polycystic ovary syndrome (PCOS). Fertil Steril. 2009; 94(1):357-359.

40. Deeks AA, Gibson-Helm ME, Paul E, Teede HJ. Is having polycystic ovary syndrome a predictor of poor psychological function including anxiety and depression? Hum Reprod. 2011;26(6):1399-1407.

41. Balen A. The pathophysiology of polycystic ovary syndrome: trying to understand PCOS and its endocrinology. Best Pract Res Clin Obstet Gynaecol. 2004;18(5):685-706.

42. Kocelak P, Chudek J, Naworska B, et al. Psychological disturbance and quality of life in obese and infertile women and men. Int J Endocrinol. 2012;2014:14.

43. Himelein MJ, Thatcher SS. Depression and body image among women with polycystic ovary syndrome. J Health Psychol. 2006;11(4): 613-625.

44. Lipton MG, Sherr L, Elford J, Rustin MH, Clayton WJ. Women living with facial hair: the psychological and behavioral burden. J Psychosom Res. 2006;61(2):161-168.

45. Ekbäck M, Wijma K, Benzein E. "It is always on my mind": women's experiences of their bodies when living with hirsutism. Health Care Women Int. 2009;30(5):358-372.

46. Messinis IE, Messini CI, Anifandis G, Dafopoulos K. Polycystic ovaries and obesity. Best Pract Res Clin Obstet Gynaecol. 2015;29(4): $479-488$.

47. Ulrich M, Weatherall A. Motherhood and infertility: viewing motherhood through the lens of infertility. Fem Psychol. 2000;10(3):323-336. 
International Journal of Women's Health

Dovepress

\section{Publish your work in this journal}

The International Journal of Women's Health is an international, peerreviewed open-access journal publishing original research, reports, editorials, reviews and commentaries on all aspects of women's healthcare including gynecology, obstetrics, and breast cancer. The manuscript management system is completely online and includes Visit http://www.dovepress.com/testimonials.php to read real quotes from published authors.

Submit your manuscript here: http://www.dovepress.com/international-journal-of-womens-health-journal 